\title{
The Types of the Body and their Impact on the Occurrence of Sports Injuries among the Students of the Faculty of Sports Science
}

\author{
D. Muhammad Alhjaya \\ Associate Professor, Department of Sports Rehabilitation, Mu'tah University \\ D. Baker Thunaibat \\ Assistant Professor, Department of Sports Rehabilitation, Mu'tah University \\ Doi:10.5296/jsr.v5i2.6205 URL: http://dx.doi.org/10.5296/jsr.v5i2.6205
}

\begin{abstract}
The study aimed to identify the body types and their impact on the occurrence of sports injuries among the students of the Faculty of Sports Science at the University of Mu'tah. The study also aimed to identify the most common sports injuries among the students of the Faculty of Sport Sciences at the University of Mu'tah . Additionally, the study aimed to identify the body types that are prevalent among the male and females students at the College of sports science at the University of Mu'tah.

The research sample consisted of male and female students from the Department of Physical Education students in the College of Sports Science, in which the researcher used the descriptive survey approach. The form of revealing injuries was also used ; besides a set of Bodily measurements for the purpose of determining the type of the body .

The two researchers used a set of statistical methods to answer the questions of the study (percentages, frequencies, (K 2) test, multiple analysis of variance (Tow-Way Anova), and Scheffe' test for post comparisons)

The study concluded that the mesomorphic type is the most prevalent type among the male and female students in the College of Sport Sciences . The study also showed that the lower limbs are the parts which are mostly injured among the students of the Faculty of Sport Sciences. The study concluded that the males are more exposed to injury than the females in the College of Sport Sciences. The results of the study indicate that abrasions or scratches are the most common types of injury among the students of the Faculty of sport Sciences.
\end{abstract}

\section{The introduction of the study:}

The curricula and training methods have been developed for the various sporting disciplines and this process required many developments in the field of sports medicine which accompanied training with more scientific studies for the preventive and 
remedial aspects. This kind of association has proven feasibility by accessing to high and standardized athletic achievements . Though sports injuries occur with varying degrees, whether in sports competitions or in scientific lessons, and that requires a treatment period that keeps the athlete away from practicing any activity which affects negatively on the physical and functional fitness as well as the level of achievement and causes some complications that may hinder the process of education and training as well as the related physiological and psychological effects on the athlete. (Kourkis, Ahmad 2012).

The body type has a direct impact on sports injuries in which (Sami'a) indicates that the influential factors in sports injuries relate to the inadequacy of the body type to the physical activity which is being practiced. (Sabban et al, 2009) also indicates that the process of identifying the types of the body for students help them to choose the appropriate physical activity, and to the importance of determining and choosing the appropriate style before they start the training process.

The study of the body types (morphology) maintained for a long time the primary concern for many researchers, until the scientist Sheldon came for more than fifty years, where he tried to discover the body description which is expected for some types of the body and then he put behavioral traits for all the body types in order to distinguish them from each other. For each one, he designed a study for the type of the body which is based on the fact that the body comprises of three main components ,these are : mesomorphic , endomorphic, and ectomorphic (. (Ta'ei, 2004)

Each physical activity has specifications for the (morphological) types of the body which are consistent with the type of skills and movements that are required for each game, which must be within the conditions that are necessary to choose a certain athlete to a particular activity, for example, when choosing a thin and tall player in gymnastics, he will be exposed to injury, especially in the back because the center of the weight of the body is away from the ground and also because of the stresses which is experienced by the spine. (Muhammad, 2002)

The qualities of the body and the body type which is distinctive for the player substantially affect the type of the practiced sporting activity. Therefore, there is always a need to conduct research to identify the distinctive body types that are appropriate for practicing a particular activity for the purposes of selection or setting educational programs or courses. And every coach has to know very well the type of body which is appropriate for the area in which he operates in order to improve the selection. (Diwan and Malih .1999)

This study shed light on a very important aspect of the aspects of the formation of the individual, the type of the body .The study focused on primary types of the body which are represented by the endomorphic, ectomorphic and mesomorphic body types , and we did not stop at this point, but we tried to identify the impact of these bodily types on the occurrence of sports injuries among the students of the Faculty of Sports Science at the 
University of Mu'tah.

The significance of the study:

This study gain its importance by identifying the types of injuries in the practiced sports activities and the role of the body type in these injuries in order to work on the establishment of the basic components to prevent students from injury and protect them as well as employing the necessary means to reduce injury, by detecting deficiencies and trying to address them by using the correct scientific methods because the study of the type of the body gives the opportunity to identify the injury before it occurs and determines the forms and types of injuries that are related to the practiced sports activity in order to protect and prevent them.

\section{The research problem:}

The problem of the study lies in identifying the relationship of the type of the body in the occurrence of injuries among students due to its danger during the performance or learning of sports activities, as well as trying to avoid its occurrence by relying on the type of the body in accepting the students who apply to colleges and departments of the Faculty of Sport Sciences. According to information of the two researchers there is shortage in the study of the relationship of the body type with sports body injuries, which called for the study of bodily types and their impact on the occurrence of sports injuries among students of the Faculty of sport Sciences.

\section{The objective of the study:}

The study aims to identify:

1. The most common sports injuries among the students of the Faculty of Sport Sciences at the University of Mu'tah.

2. The body types that are prevailing among the male and female students in the College of Sports Science at the University of Mu'tah.

3. The most vulnerable areas to injury among the students of the Faculty of Sports Science at the University of Mu'tah.

4. The statistically significant differences regarding the number of injuries which are experienced by the students of the Faculty of Physical Education at the University of Mu'tah, according to the study variables (gender, body type ).

\section{The questions of the study:}

1. "What are the most common sports injuries among the students of the Faculty of Sport Sciences at the University of Mu'tah?"

2. "What are the prevailing body types among the male and female students in the College of Sports Science at the University of Mu'tah?" 
3. "What are the most exposed areas to injury among the students of the Faculty of Sports Science at the University of Mu'tah?".

4.

5. "Are there statistically significant differences regarding the number of injuries that are experienced by the students of the Faculty of Physical Education at the University of Mu'tah, according to the study variables (gender, body type )."

\section{The areas of the study:}

The human area: The students of the Faculty Sports Science at the University of Mu'tah for the academic year (2013-2014)

Temporal area: From 03/15/2014 up to 05/13/2014

The spatial domain: The teaching halls and indoor hall and the outside courts at the College of Sports Science.

\section{The previous studies:}

Salama (1997) Conducted a study that aimed to identify the relationship of some of the morphological and physical variables as well as the type of the body with sports injuries that are common among the students of Physical Education .The study sample consisted of 84 students of the faculty of Physical Education, at the University of Al Mina . 42 of those students were injured, while the other 42 who weren't injured .The morphological variables included ( length and weight _ while physical variables included flexibility and Fitness). The study concluded that muscle injuries reached the highest proportion of injuries, followed by the joints. The endomorphic type occupied the first rank for both inured and non-injured, the mesomorphic type was in the second rank_ and finally, the endomorphic type in the last rank .

Ta'ei (2004) conducted a study which aimed to identify the impact of the type of the body (endomorphic - mesomorphic - endomorphic) on the occurrence of ligaments injuries of the knee joint. The research sample included (13) students of the first stage. The researcher used the descriptive method survey, and the form of revealing injuries was also used .In addition a set of body measurements was used for the purpose of determining the type of the body depending on the method of the body type for Heath - Carter (and the study concluded that the _mesomorphic type is the least type that is vulnerable to injury regarding to the ligaments of the knee joint, while the most vulnerable type was the ectomorphic type followed by the endomorphic type.

Mohammed (2002) conducted a study that aimed to identify the types of sports injuries, their causes, their locations as well as the activities under which they occurred among the students of the Faculty of Physical Education at the University of Baghdad during the early four stages. The study included 204 injured from the students . The researcher used the field survey as a method for conducting the study, and the study 


\section{Macrothink

concluded that there is a high percentage of injuries in the Faculty of Physical Education, especially in the early stages( the first and second stage), and there is a high rate of injuries and especially for the lower limbs , particularly the knee and ankle joints .

Kourkis, and Ahmad (2012) conducted a study which aimed to identify the relationship of the type of the body ( endomorphic - mesomorphic - ectomorphic) in the incidence of injuries of the lower limbs as a result of practicing in Sports Games in practical lessons in the Faculty of Physical Education. The sample consisted of 77 students from the Faculty of Physical Education. The sample was selected in the intentional method to include those who have sports injuries in the lower limbs. The researchers used the descriptive method survey in order to fit the nature of the study, and the study concluded that there are no morally significant differences between the ectomorphic type and the injuries which are under consideration, and the study did not show any significant differences between the mesomorphic type and sports injuries, while there are significant differences in the value of (r) which is calculated between the endomorphic type and the injuries which are under consideration.

\section{Comment on the previous studies:}

From the review of the previous studies and researches, it is evident that they have been concerned with studying the types of the body and sports injuries while the studies were characterized by scarcity in general .

Based on what has been exposed from the previous studies, we can draw the following conclusions:

1. The previous studies agreed on the importance of studying the type of the body, and its impact on the occurrence of injuries as well as its importance during performing and learning sports activities, and trying to avoid the occurrence of them by relying on the type of the body in the admission of students and the selection of athletes. These studies used the descriptive method, It also used the form of revealing injuries as well as using a set of body measurements for the purpose of determining the type of the body. Most of the previous studies were similar in the methods and statistical processing which were used.

2. The researcher benefited from all these studies as follow :

- The identification and deep understanding of the problem of the study.

- Formulating the objectives and questions of the study.

- Choosing the appropriate methodology for the study objectives, and the appropriate statistical methods to answer the questions of the study.

The two researchers believe that the most important thing that distinguishes this study from the previous studies is that: 
1. - It is one of the first studies that aimed to identify the impact of the type of the body (endomorphic - mesomorphic - ectomorphic ) in the incidence of sports injuries among the students of the Faculty of Sport Sciences at the University of Mu'tah . The researchers also used the modern tools and devices to identify the type of the body and fat percentage such as the device of (Body Fat Analyzer)

\section{The methodology of the study:}

The researcher used the descriptive method by following the method of survey with its scientific steps and procedures due to its appropriateness to the nature of this study.

\section{The community and the study sample:}

The community of study: The study population consisted of the students from the Department of Physical Education at the Faculty sports science at various academic levels (first, second, third, fourth) who were enrolled in the academic year 2013-2014, with a total number of $(\quad)$.

The study sample: The study sample consisted of ( ) students from the Department of Physical Education, in the Faculty of Sports Science. The research sample was chosen in the intentional way which excludes the injured.

\section{The study variables:}

First, the independent variables which include:

- sports injury

- The type of the body (endomorphic - mesomorphic - ectomorphic ).

- Gender: (male, female)

- The type of the injury site : ( upper, lower)

Second, the dependent variables:

The form of detecting injuries

Body measurements for the purpose of determining the type of the body.

\section{The researcher used the following devices and tools:}

1. A device for measuring weight

2. A tape for measure length

3. A device for measuring obesity ( body fat analyzer )

4. A questionnaire for measuring the injury.

\section{The Statistical methods:}

The researcher used a range of statistical tools to answer the questions of the study.

The percentages, frequencies and ( K 2) test

Tow-Way Anova

Scheffe' test for post measurement 
The exploratory experiment:

The exploratory experiment was conducted to a sample that consisted of (8) students from the students of the Faculty of Sports Science from the total study Community who were chosen in the intentional method and then the injured were excluded from the study sample .The experiment aimed at identifying the advantages and disadvantages that may appear while performing the tests in order to avoid them, and applying the measurement methods and identifying their suitability for Testing as well as training on the recording method, in addition to teaching the working team about how to implement and record the tests and measurements. While conducting the exploratory experiment the researcher concluded the following :

- The compatibility of the devices and tools which are used in the tests and measurements.

- The validity of the questionnaire and the ability of the research sample to answer the items of the questionnaire which was used in the research.

The scientific coefficients for the tests :

The validity and reliability of the tool:

In order to conduct this study, the research used a range of devices and tools that have shown reliability and validity for the measurement in the field of sports. They are considered as the devices which were manufactured very precisely and the reliability of these devices has become axioms of measurement in addition to relying on the opinions of some experts in the field.

\section{The steps of conducting the study:}

The researcher has taken some of the regulatory procedures for the preparation of the study including the following steps:

The study community was limited to the records of admission and registration at the University of Mu'tah.

The researcher has designed a special questionnaire to collect data and determine the injury site .

\section{$\square$ The study was conducted in two stages:}

The researchers and their assistants took the physical measurements (height, weight, percentage of body fat).

$\square$ The researchers distributed the questionnaire which is related to the sports injuries.

\section{Preface :}

The following is a detailed presentation of the results of the study in the light of its raised questions which aimed to detect the impact of some (morphological) variables 
on a number of the injuries which are experienced by the students of the Faculty of Physical Education at the University of Mu'tah. The following is a presentation of the results of the study according to the sequence of its questions:

\section{The results of the first question, which asks :}

"What are the most common sports injuries among the students of the Faculty of Sport Sciences at the University of Mutah?"

In order to answer this question, percentages and frequencies were extracted for the responses of members of the study sample who were exposed to identified injuries in the current study which were represented by ( fractures, rupture of tendons, rupture of muscles, dislocation , sprains, bruises of bones, bruises of muscles, bruises of nerves, wounds, spasms, contortion, abrasions or scratches), in which the number of the students who have been subjected to injuries of different kinds was (110) students and they represented $(73 \%)$ of the study sample, as was use the test (K 2) to detect the significance level of differences in the rates of injury according to its type .Table (1) shows the results of that.

Table (1):The percentages and frequencies and test (K 2) according to the type of the sports injury.

\begin{tabular}{|c|c|c|c|c|c|}
\hline The type of injury & frequency & percentage & rank & & $\begin{array}{l}\text { Significance } \\
\text { level }\end{array}$ \\
\hline Abrasions or scratches & 31 & 0.32 & 1 & \multirow[t]{14}{*}{513.82} & \multirow[t]{14}{*}{$* 0.00$} \\
\hline Contractions & 25 & 0.12 & 2 & & \\
\hline rupture of tendons & 20 & 0.10 & 3 & & \\
\hline rupture of muscles & 16 & 0.08 & 4 & & \\
\hline contortion & 12 & 0.08 & 4 & & \\
\hline rupture of ligaments & 11 & 0.06 & 5 & & \\
\hline dislocation & 9 & 0.05 & 6 & & \\
\hline sprains & 6 & 0.04 & 7 & & \\
\hline bruises of bones & 4 & 0.04 & 7 & & \\
\hline Fractures & 7 & 0.04 & 7 & & \\
\hline wounds & 9 & 0.03 & 8 & & \\
\hline Bruises of muscles & 19 & 0.02 & 9 & & \\
\hline Bruises of verves & 80 & 0.02 & 9 & & \\
\hline Total & 149 & $100 \%$ & - & & \\
\hline
\end{tabular}

statistical significance at $(\alpha \leq 0.05)$ 
Table (1) Shows that the injury rate of "scrapes or scratches, was the highest with a percentage of (32\%) of the total injuries which are experienced by the students of the Faculty of Sports Science at the University of Mu'tah, followed by contractions with a percentage of (12\%), then the rupture of tendons (10\%), abrasions (8.3\%), wounds by (6.3\%), sprains (4.3\%), followed by the same percentage for each of the (ruptures muscle and contortions) with a percentage of $(8 \%)$, then the rupture of the ligaments $(5 \%)$, then all of the injuries (sprain, bruises, fractures) with a percentage of $(4 \%)$ for each of them, then the wounds with a percentage of $(3 \%)$ and finally the injuries of (bruises muscles, bruises nerve) in the last rank with a percentage $(2 \%)$. The value of K2 which equals (513.82) and the accompanying level of significance shows the morale of the differences in the rates of injury according to their types. Figure (1) illustrates the variation in the rates of injury according to their types.

The researchers attribute the occurence of "scrapes or scratches, which reached a percentage of (32\%) among the injuries experienced by the students of the Faculty of Sports Science at the University of Mu'tah, to the fact that the skin injuries in general are common injuries in the different kinds of sports as the skin forms the external and basic surface of the body. Therefore, it is always exposed to more injuries, during practicing sports activities either in the indoor halls or in the outside courts, and the most important of these skin injuries are "scrapes or scratches, which "is a scrape to the surface layer of the skin that occurs when the athlete slides or falls on a hard or steel object. (Mohammad, 2004)

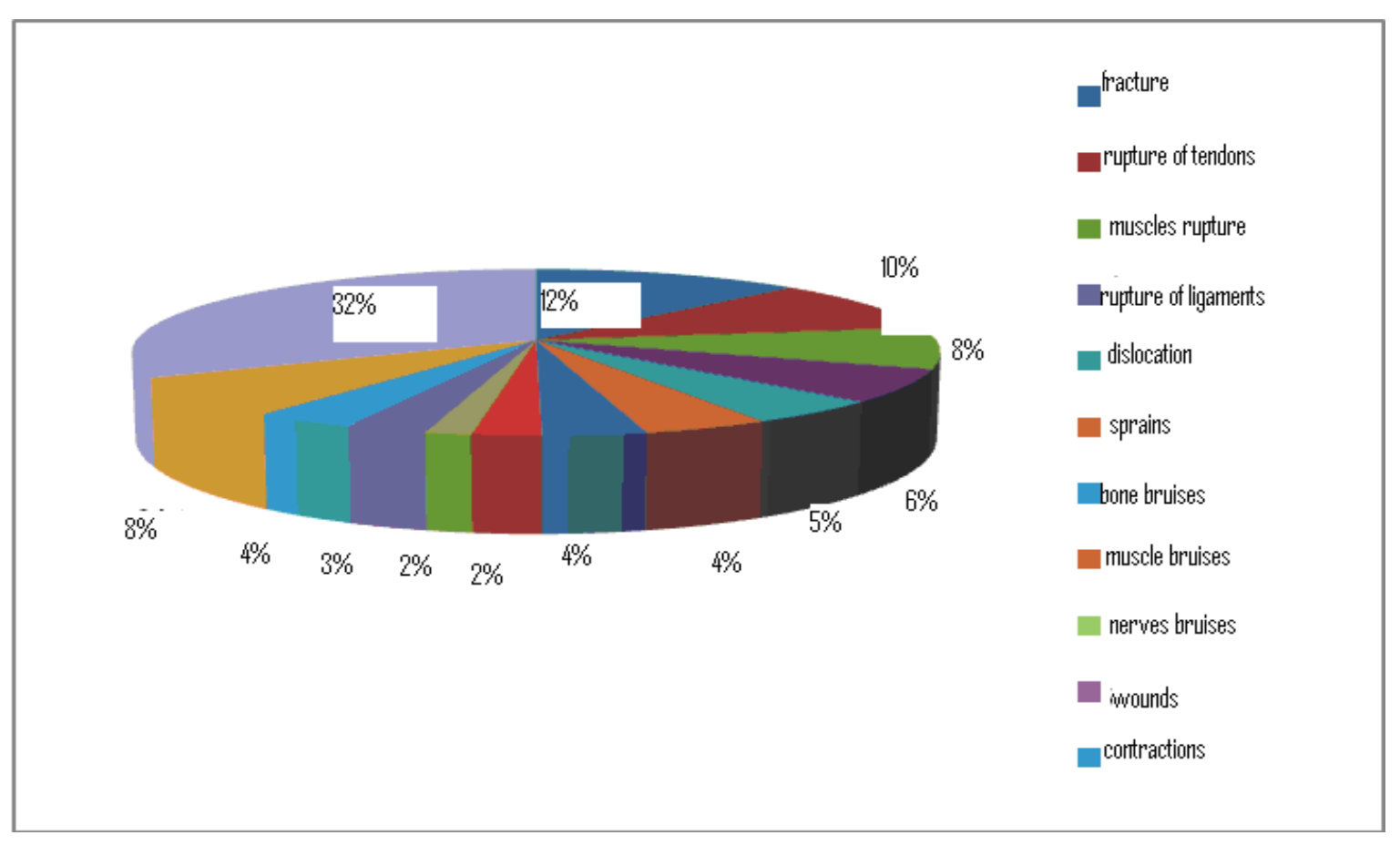

Figure (1) 
Difference in injury ratios according to its type

- The results of the second question, which asks:

- What are the most prevailing body types among the male and female students in the College of sports science at the University of Mutah?

In order to answer this question percentages and frequencies were extracted for the types of the body of the students, according to gender (male, female), test (K2) was also used to detect the level of significance of the differences in percentages. Table 2 shows the results of that.

\begin{tabular}{|c|c|c|c|c|c|c|c|}
\hline \multirow{2}{*}{$\begin{array}{l}\text { Level of } \\
\text { significa } \\
\text { nce }\end{array}$} & & \multicolumn{4}{|c|}{ The type of the body } & \multicolumn{2}{|l|}{ gender } \\
\hline & & total & ectomorphic & endomorphic & mesomorphic & & \\
\hline \multirow{6}{*}{$* 0.00$} & \multirow{6}{*}{$\begin{array}{l}20.7 \\
2\end{array}$} & 82 & 5 & 16 & 61 & number & \multirow[t]{2}{*}{ male } \\
\hline & & $100 \%$ & $6.1 \%$ & $19.5 \%$ & $74.4 \%$ & percentage & \\
\hline & & 68 & 24 & 7 & 37 & number & \multirow[t]{2}{*}{ female } \\
\hline & & $100 \%$ & $35.3 \%$ & $10.3 \%$ & $54.4 \%$ & percentage & \\
\hline & & 150 & 29 & 23 & 98 & number & \multirow[t]{2}{*}{ total } \\
\hline & & $100 \%$ & $19.3 \%$ & $15.3 \%$ & $65.3 \%$ & percentage & \\
\hline
\end{tabular}

Table (2) shows that the mesomorphic was the most common body type among the students of physical education which formed about $65.3 \%$ among the total number of the students. Then, the ectomorphic type with about $19.3 \%$ among the students of the faculty of sport science at Mu'tah university. The indomorphic type was in the last rank with about $15.3 \%$. The body types among the female students were as follow : mesomorphic type , 54.4\% ; ectomorphic, 35.3\%, and endomorphic $10.3 \%$. T he body types among the male students were as follow ( mesomorphic , 74.4\% ; endomorphic , 19.5\%, and ectomorphic , 6.1\%). It also shows the amount of K2 with about (20.72) and the level of significance of the accompanying morale differences in percentages between the males and females according to the types of body, which suggests that the bodily types differ between the male and female students at the College of Sports at the University of Mu'tah.

The two researchers attribute that to the physical (aerobic) endurance training leads to raising the efficiency and effectiveness of the muscle fibers which has slow sprain, while lead physical training violent and short-term to improve the efficiency and effectiveness of the muscle fibers that has rapid sprain, and this is characterizes the study 
plan for the students in the Department of Physical Education in the Faculty of Sport Sciences at the University of Mu'tah, where the percentage of practical materials in the study plan of the department reaches up to $80 \%$ of the total plan of study. This percentage of the practical material of the study plan (aerobic and anaerobic) motivates the aerobic physical endurance training to strengthen muscle fibers of the slow sprains, thus leading to their development, while the violent physical training leads to the employment of the muscle fibers which have fast sprain, and thus lead to the development of such fibers. (Hazza.2004)

The two researchers also attribute this result to the fact that the students who enter the Department of Physical Education at the Faculty of Sport Sciences, are those who have the mesomorphic type, where the largest proportion of acceptances in sporting excellence are accepted in the specialization of Physical Education in which these students have a certain percentage of muscle fibers that are attributed to heredity as indicated by Hazza (2004). These are developed through the practical courses which have previously been noted as they reach up to $80 \%$ of the courses offered in the study plan.

\section{The results of the third question, which asks:}

"What is the area that is most exposed to injury among the students of the Faculty of Sports Science at the University of Mu'tah?".

In order to answer this question percentages and frequencies have been extracted for the site of the injury (lower, upper), (K 2) test was also used to detect the level of significance of differences in the percentages of the site of injury as determined by the members of the study sample. Table 3 shows the results of that.

Table (2):Percentages and frequencies and test (K2) for the anatomic site of injury

\begin{tabular}{|l|l|l|l|l|l|}
\hline The injury site & Frequency & Percentage & Rank & Ka2 & $\begin{array}{l}\text { Significance } \\
\text { level }\end{array}$ \\
\cline { 1 - 4 } lower & 1 & $67 \%$ & 168 & 60.75 & 0.00 \\
\cline { 1 - 4 } upper & 2 & $33 \%$ & 63 & & \\
\cline { 1 - 3 } & - & $100 \%$ & 249 & & \\
\hline
\end{tabular}

statistical significance at $(\alpha \leq 0.05)$

Table (3) shows that the most vulnerable sites for sports injuries among the students of the Faculty of Sport Sciences at the University of Mu'tah were the lower area with a percentage of $(67 \%)$ of the total casualties that are experienced by the students .The second and last rank is the upper area with a percentage of (33\%). The results of tracing the value of $\mathrm{K} 2$ which equals (60.75) and the accompanying level of significance also show the morale differences in the percentages of the areas of injury (upper, lower), which are experienced by the students of the Faculty of Sports Science at the University. 
The two researchers attribute this result to the fact that the lower parts of the body (such as the ankle, knee and spine) carry more weight than the upper parts, and that the wrong performance (the wrong technique ) as well as the inadequacy of the warm-up and exceeding the physiological natural limits during the performance of some of the students exert pressure on these parts and thus makes the center of weight unstable, which causes unbalanced effort on these organs which increases the probability of being struck, more than that possibility of injury in the upper part.

\section{The results of the fourth question, which asks:}

Are there statistically significant differences regarding the number of the injuries that are experienced by the students of the Faculty of Physical Education at the University of Mu'tah, according to the study variables (gender, physical style).

In order to answer this question a Tow-Way Anova was used to detect differences of the number of injuries, according to the study variables (gender, body type). Table 4 shows the results of that.

Table (4):A Tow-Way Anova table for the detection of differences regarding the number of injuries according to the variables of (gender, body type)

\begin{tabular}{|l|l|l|l|l|l|}
\hline $\begin{array}{l}\text { Variance } \\
\text { source }\end{array}$ & $\begin{array}{l}\text { Number of } \\
\text { squares }\end{array}$ & $\begin{array}{l}\text { Degree of } \\
\text { freedom }\end{array}$ & $\begin{array}{l}\text { Average of } \\
\text { squares }\end{array}$ & F value & $\begin{array}{l}\text { Significance } \\
\text { level }\end{array}$ \\
\hline Gender & 6.698 & 1 & 6.698 & 9.723 & $* 0.002$ \\
\hline Body type & 5.481 & 2 & 2.741 & 3.979 & $* 0.021$ \\
\hline $\begin{array}{l}\text { Gender } \\
\text { body type }\end{array}$ & 2.063 & 2 & 1.032 & 1.498 & 0.227 \\
\hline error & 99.193 & 144 & .689 & & \\
\hline total & 531.000 & 150 & & & \\
\hline
\end{tabular}

- statistical significance at $(\alpha \leq 0.05)$

The data contained in table (4) Show that there are statistically significant differences at the level of significance $(\alpha \leq 0.05)$ regarding the number of injuries experienced by the students of the Faculty of Sports Science at the University of Mu'tah according to the variables of gender and body type, and there were on differences attributed to the effect of the interaction between the variables.

According to gender, the average number of injuries among the males was (2.91) and among females was (2.64), which indicates that males are more exposed to injury than females

In order to detect the differences according to the variable of the body type , Scheffe' test was used, and table 5 illustrate the results of that . 
Table (5):Scheffe' test results for the post comparisons to detect the differences in the number of injuries according to the variable body type

\begin{tabular}{|l|l|l|l|l|}
\hline Mean & Groups & differences \\
\cline { 3 - 5 } & & mesommorphic & endomorphic & ectomorphic \\
\hline 2.01 & mesommorphic & - & $-1.39^{*}$ & $-0.89^{*}$ \\
\hline 3.40 & endomorphic & $1.39^{*}$ & - & $0.50^{*}$ \\
\hline 2.90 & Ectomorphic & $0.89^{*}$ & -0.50 & - \\
\hline
\end{tabular}

Data in the table (5) show that all the differences were statistically significant and were in favor of the endomorphic type followed by the ectomorphic type type, and finally the students of mesomorphic type. (Ta'ei, 2004)

The two researchers attribute to the fact that the extra the weight of the athlete or the practitioner of the physical activity will be at the expense of the fat mass that accumulated under the skin (stored fat) and that is an impediment to the muscular work while performing aerobic exercise or playing in any activity. The overweight of the athlete increases the consumption of the stored energy and that leads to an early stage of fatigue and if he/she continues in practicing the physical activity, there will be a stage of strain and overload and thus leads to the occurrence of injury. (Hajjar, 2002)

The two researchers attribute the lack of injuries in the mesomorphic type to the muscle and ligaments strength of this type, as the strength of the muscles of the body, especially the lower limb tighten the ligaments joints and thus increase the strength of the stability of the joints and decreases the probability of the rupture injuries in ligaments, which results from the pulling or sprains. Athletes who have a mesomorphic body type are less prone to injury because their muscular mass own protect their joints and ligaments, and thus the probability of injury is coupled with the weakness in the muscles for both the upper or lower parts. (Taei, 2004)

The researchers attribute that to the endomorphic type which is characterized by overweight that result from the component of fat at the expense of component of muscles which, in turn, exerts more weight and pressure on the joints and ligaments, leading to strain to the joints and ligaments and thus leads to the possibility of being injured. The increase in component of fat at the expense of component of muscle makes the muscles of the lower limb less powerful and this affects the safety of the stability of the joints and ligaments, because the joint in the lower limbs depends on the strength of the front thigh muscles in their persistence and stability ( The muscle with four heads of thigh) and the quadriceps back as well as the leg muscles. (Taei, 2004)

The ectomorohic type also leads to a weakness in the joints and ligaments due to the lack of muscle component which is necessary for the its persistence and stability, and this weakness in the muscles leads to the ease of injuries through the inability of the joints to carry the rotational and sudden movements or external shocks. 


\section{Macrothink}

(Taei, 2004)

\section{Conclusions:}

In light of the findings of the study and the discussion of it can be concluded the following:

1. The mesomorphic type is the body type which is prevailing among the male and female students in the Faculty of Sport Sciences.

2. The lower limb is considered as the most injured part among the students of the Faculty of Sport Sciences.

3. Males are more exposed to injury than females in the Faculty of Sport Sciences.

4. The most common types of injury among the students of the Faculty of Sports Science are"abrasions or scratches"

\section{Recommendations:}

In light of previous findings, the two researchers recommends the following:

1. preparing students theoretically by giving them lectures about sports injuries in terms of the mechanism of I their occurrence, causes and methods of prevention.

2. Paying more attention to physical preparation and the quality of body type and raising the level of fitness of students, as well as strengthening the muscles and ligaments that are related to the most vulnerable areas to injury.

3. Paying more attention to good warming up and teaching students and familiarizing them with the importance of warming up and its role in reducing the incidence of sports injuries and reducing their severity.

4- Identifying the type of the type body of the students who are admitting for acceptance by means of the specific exams for accepting the students in the faculty of physical education .

5- Planning for future studies about injuries and body types in general and the injuries of the lower part of the body in particular .

\section{References:}

1. Diwan, Lamia Hassan Mohammed and Malih, Fatima Abd (1999) type body and its relation to the level of learning some skills fencing" the journal of a university teacher number 204.

2. Saluma, Emad Dawood (2010), "the types of the body as a function to predict some of the psychological characteristics of an emerging football ages (16.17 years) in the districts of the province of Babylon," Journal of the Science of Physical Education, the first editionthe third volume.

3. Mujally, Majid Fayez (2007), "sports injuries among practitioners of sports activities in the fitness centers in Jordan," studies of, Educational Sciences, Volume 34, Issue 2 


\section{Macrothink}

4. Hammad, Mufti Ibrahim, and Aldroy, Mohsen Eissa (2001) "identifying the common causes of injuries among football players in the different centers" the University of Mosul / College of Education Basic - Department of Physical Education.

5. Mujally, Majid, Bakeer, Muhammad, and Al Hindawi, Muhammad (2010), "an analytical study of sports injuries among goalkeepers of football in Jordan." Najah University Journal for researches (the Human Sciences (Vol 24.

6. Mujally, Majid and Halawah, Rami, and Al Rahahleh, Walid (2002), "sports injuries common to athletes," Al-Najah University Journal for Researches (Humanities) volume 22.

7. Muhammad, Smi'a Khalil (2002), "an analytical study of sports injuries among the students of the Faculty of Physical Education at the University of Baghdad," the journal of Physical Education - the eleventh volume - the first edition.

8. Kourkis, Shatha Hazim, Ahmad, Omar Aladdin (2012), "bodily patterns and their relation to lower limb injuries," Journal of Kirkuk University for Humanistic Studies Volume: 7 Issue 3.

9. Hazza, Hazza bin Muhammad (2004), the muscle fibers and their role in physical performance, King Saud University, Riyadh - Kingdom of Saudi Arabia.

10. Salama, Bahey El Din Ibrahim (1997), " the relationship of some morphological and physical variables and the body type with the common sports injuries among the students of Physical Education, Journal of Arts , issue number 19

11. Abdullah, Sidi (2009), "Trends of some bodily types toward the physical self-awareness in the lesson of physical education," Faculty of Human and Social Sciences, the Institute of Physical Education

12. Hajjar, Taha Yassin (2012) Lectures about the physiology of sports training, Faculty of Physical Education, the University of Mosul.

13. Radwan, Mohamed Nasr El Din (1997), the reference in the bodily measurements, the Arab Thought House, Cairo.

14. Sabban, Muhammad and others (2009). The role and importance of identifying the types in the evaluation of secondary schools curriculum in Algeria, a research published in the Journal of Sports Sciences, the first edition, the University of Diala.

15. Ta'ei, Osama Ahmed Hussein (2004) body types and their impact on injuries to the ligaments of the knee joint among the students of the Faculty of Physical Education, research published in the Journal of Physical Education, Volume 13, the second Issue, Iraq. 
16. Akkam, A'yid Muhammad Shafiq (2005) relationship of the body type and the physical self with practical achievement among the students of the Faculty of Physical Education, Unpublished Master Thesis, Faculty of Physical Education, the University of Mosul.

17. Muhammad, Smi'a Khalil (2002), an analytical study of sports injuries among the students of the Faculty of Physical Education, published research in the Journal of Physical Education, Volume 11, the first edition, Baghdad, Iraq.

18. Muhammad, Smi'a Khalil (2004), sports injuries, University of Baghdad Press, Iraq. 